\title{
TUNNEL EXCAVATION IN CLAYEY-MARLY FORMATIONS: THE CASE OF KALLIDROMO TUNNEL
}

\author{
Diasakos Nikolaos ${ }^{1}$, Amerikanos Panagiotis ${ }^{1}$, Tryfonas Georgios ${ }^{1}$, \\ Vagiotou Eleni $^{1}$, Baltzois Vassilios ${ }^{1}$, Bloukas Stavros ${ }^{1}$, Tagkas Theodoros ${ }^{2}$, \\ Malandrakis Eleftherios ${ }^{2}$, Poulakis Nikolaos ${ }^{2}$, Kalogerogiannis Georgios ${ }^{2}$, \\ Tsirigotis Nikolaos ${ }^{2}$ \\ ${ }^{1}$ ERGOSE S.A., supervision team, paamerikan@ergose.gr, gitryfonas@ergose.gr \\ ${ }^{2}$ TERNA S.A., tunnel section construction, ternakallidromo@tee.gr
}

\begin{abstract}
This paper presents the excavation of Kallidromo railway tunnel in clay and clay-marl formations. During the past years various approaches were considered both at the design and construction level, for the completion of this difficult part of the tunnel. Finally a method has been selected and successfully applied which combines the principles of yielding and double support.
\end{abstract}

Key words: Kallidromo tunnel, clay formations, yielding support, double support.

\section{Indroduction}

The paper presents the excavation of Kallidromo twin-tube single-track tunnel in clay - clay-marl formations. The excavation was based on a method which combines the yielding and double support principles, modified according to the approved designs, instrumentation measurements and the tunnel conditions that were encountered.

\section{Project description}

The twin-tube single-track tunnel of Kallidromo is part of the New High-Speed Railway Line Tithorea - Lianokladi, in the section from Tithorea Railway Station Ch. $0+000$ to Ch. $19+000$. The said line is a subsection of the railway line connecting Athens to Thessaloniki (Fig. 1). The railway tunnel has two tubes $9.034 \mathrm{~m}$ long each, a net cross-section of $58 \mathrm{~m}^{2}$, a design speed of $250 \mathrm{~km} /$ hour, cross-cuts every $500 \mathrm{~m}$, elevation approx. $200 \mathrm{~m}$ and a longitudinal decrescent gradient of $6 \%$ o towards north. It runs in a general North-South direction and it is going to be the longest tunnel in Greece. The proj-

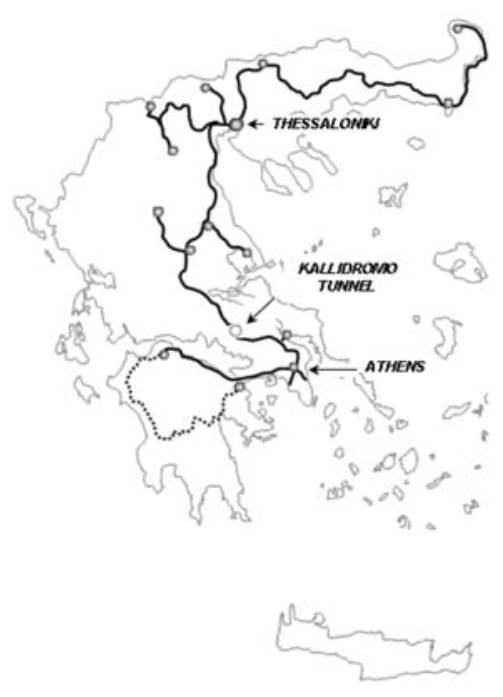

Fig. 1: Greek railway net. Location of the Kallidromo tunnel. 


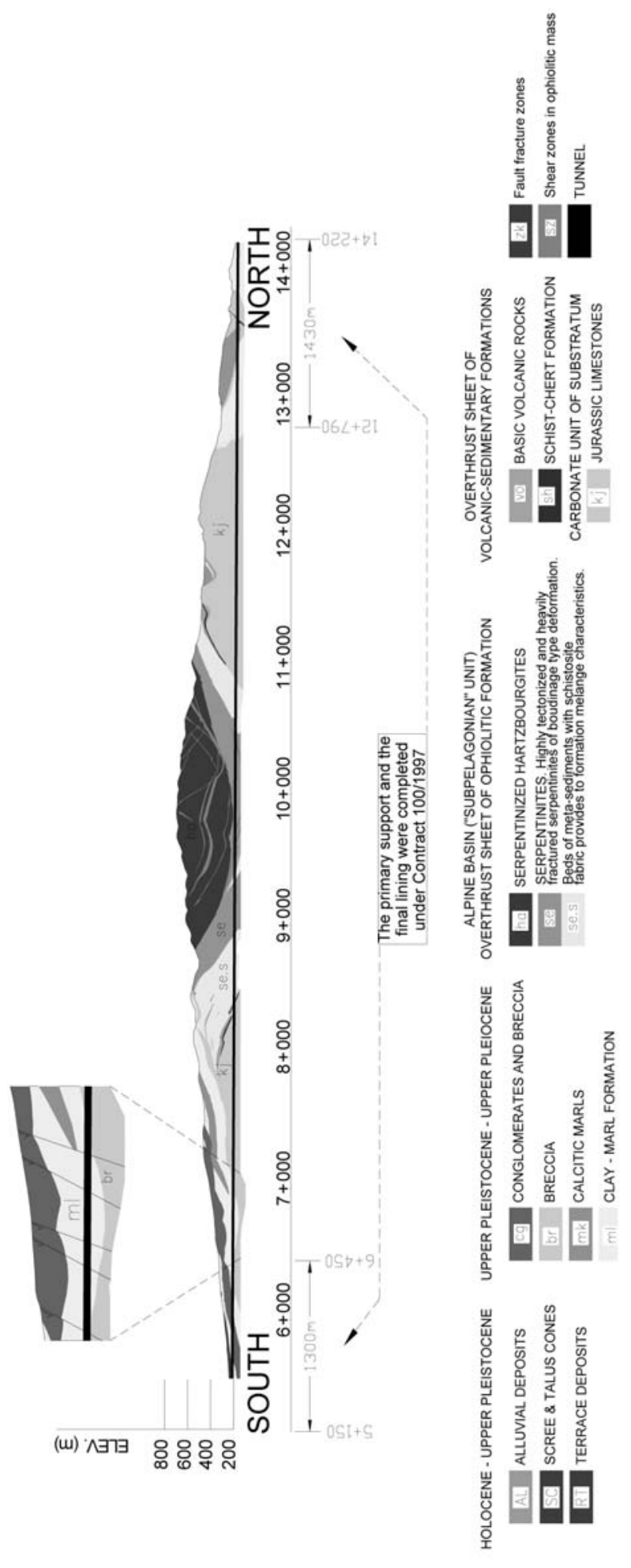

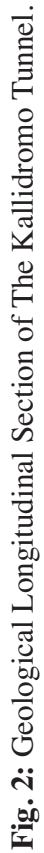




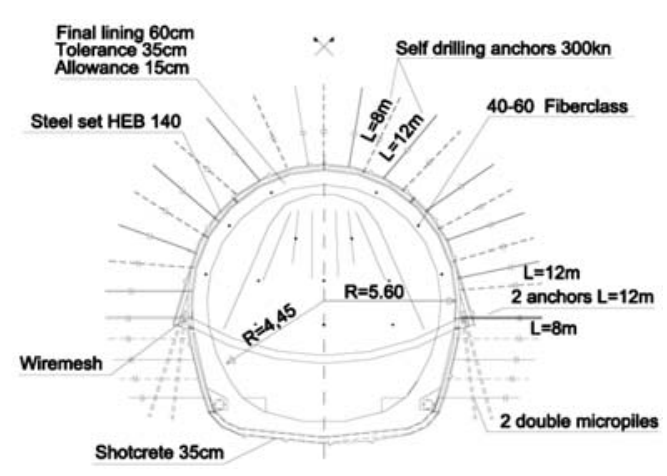

Fig. 3: Cross section of initial design S6.1c.

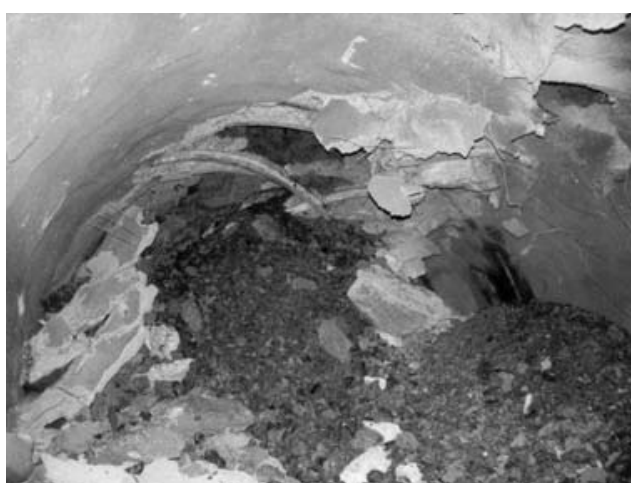

Fig. 4: Collapsed area in the right tube.

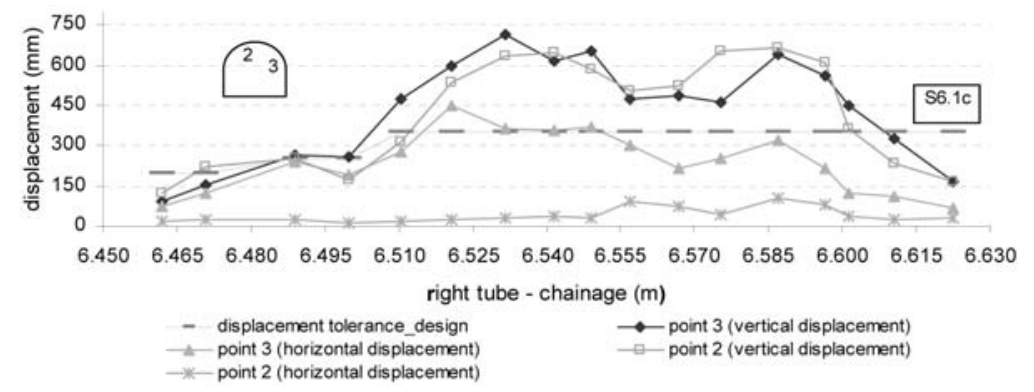

Fig. 5: Displacements close to collapsed area.

ect is a continuation of a previous contract (No 100/1997) under which $1.300 \mathrm{~m}$ were excavated from the South drive and $1.430 \mathrm{~m}$ from the North drive in each tube and final lining was installed in $1.300 \mathrm{~m}$ of each drive respectively.

\section{Geology of the tunnel area}

The area of interest (Fig. 2) mostly consists of Alpine formations of the Pelagonian zone, which also constitute the bedrock of the area, and the overlying Post-Alpine formations and deposits. Maximum overburden is $540 \mathrm{~m}$, approximately in the middle of the tunnel. Alpine formations are divided as follows, from bottom to top:

- Carbonate bedrock unit: Bituminous limestone dating back to the Upper Triassic - Upper Jurassic (kj)

- Tectonic cover of volcano-sedimentary formations: Shale, chert, sandstone, marly limestone and basaltic pillow lavas (vo)

- Ophiolitic tectonic cover from bottom to top:

- Schistose serpentinite (se.s)

- Serpentinite (se)

- Serpentinized hartzburgite (ha)

Based on their structure and composition, schistose serpentinites are described as ophiolitic mélange. Post-Alpine formations are divided as follows, from bottom to top:

- Upper Pliocene - Upper Pleistocene formations 


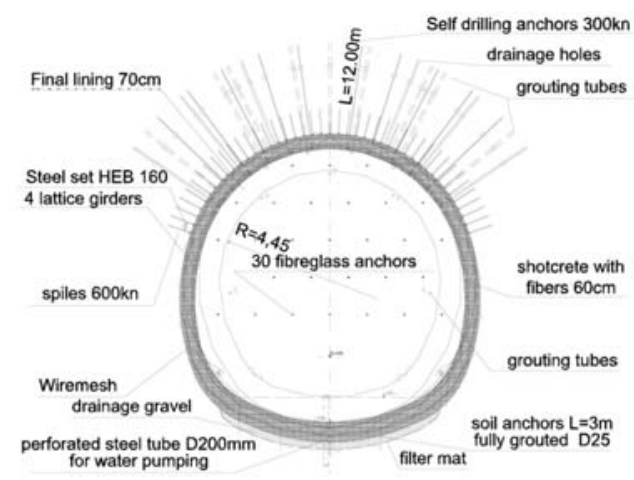

Fig. 6: Rehabilitation cross section S3.A.

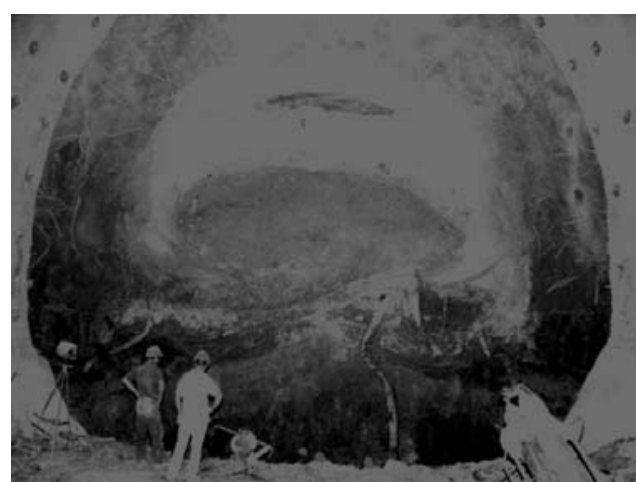

Fig. 7: Old colapsed tunnel during re-excavation.

- Conglomerate-breccia (br)

- Clay-marl formation (ml)

- Calcitic marl (mk)

- Limestone conglomerate (cg)

- Formations and deposits of the Upper Pleistocene - Holocene

- Terrace Deposits (RT)

- Scree \& Talus Cones (SC)

- Alluvial Deposits (AL)

The area referred to below is the area of the clay-marl formations $(\mathrm{ml})$ of the south drive from Ch. 6+470 to Ch. 7+115 (645m long, see Fig. 2), where the height of the overlying formations starts from $120 \mathrm{~m}$ and reaches about $230 \mathrm{~m}$. This formation is very heterogeneous and mainly consists of alternating intercalations of tenacious blue-grey schistose clay, locally containing grey-white calcitic concretions, and intercalations of tenacious dark brown clay. There are also encountered lenses and intercalations of medium to coarse-grained sand with an average thickness ranging approximately from $0,20 \mathrm{~m}-2,00 \mathrm{~m}$. More rarely the formation contains lenticular intercalations of conglomerates. At its base there are interbeds of organic material.

In terms of grading, the formation is mostly classified as lean (CL) and fat (CH) clay, whereas the sandy intercalations as silty (SM) and clayey (SC) sand. Locally there are intercalations characterized as clayey-sandy silt (ML). The formation has a medium to high plasticity and a high swelling potential.

\section{Description of temporary support measures implemented in the past}

The tunnel excavation from the South drive started under an older contract (No 100/1997) and about $1.400 \mathrm{~m}$ in total were excavated from each drive. In the "ml" formation (from Ch. $6+470$ to Ch. 6+665 in the right tube) support measures (category S6.1c) included 30cm thick shotcrete, steel sets HEB 140, wiremesh and self-drilling anchors with a bearing capacity of $300 \mathrm{kn}$ and $600 \mathrm{kn}$. Excavation was performed in three phases. Phase A (top heading) included the enlargement of the steel set foundation (elephant foot), foot micropiles and primary reinforcement of the tunnel face with fibreglass anchors (see Fig. 3). In addition, in order to minimize displacements during Phase A the working floor was closed with a temporary invert, reinforced with double wiremesh. The convergences measured were in the order of $70 \mathrm{~cm}$ (see Fig. 5), which lead to repeated reconstructions of the cross-section. However, approximately at Ch. $6+625$ in the right tube the tunnel collapsed (Fig. 4) over about 40m and as a result excavation works were stopped. We note the following issues in order to show the extent of adverse conditions affecting this par- 


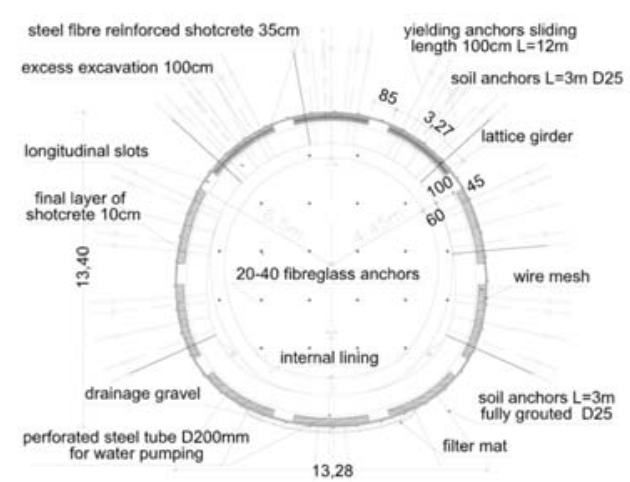

Fig. 8: Yielding cross section Y45.g

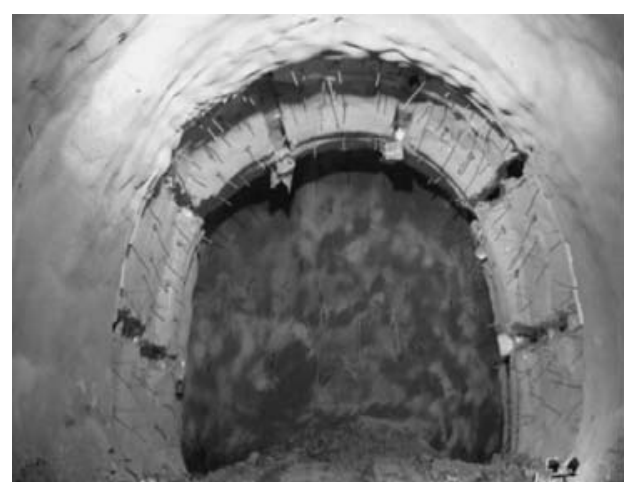

Fig. 9: Yielding cross section Y45.g - primary support.

ticular part of the project:

- The area is characterized by recent lacustrine deposits with inherently unfavourable technical-geological characteristics.

- Formations have a clayey, clayey-marly composition with slickensides and local intercalations of sandy lenses.

- Clays mainly consist of minerals such as montmorillonite, and in general they are highly swelling.

- Formations have low strength in relation to the stresses imposed by the overburden, thus creating squeezing conditions.

- The layout of the tunnels (twin tunnels) provides for a small axial distance between the two tubes $(35 \mathrm{~m})$ and creates negative interactions during the excavation and support phases.

- The tunnel overburden is high for this type of geological formations.

In addition to the above, the following unexpected disfavouring factors were also identified, and are summarized below:

- Wandering flows were observed and the groundwater table was not easily detectable due to the low primary water permeability of the formations.

- Clay strength reached extremely low levels (residual - ultimate strength) under continuous loading and slow deformation (strain-softening behaviour).

- Water influx was facilitated by increased permeability zones (sandy intercalations) as well as by the loosening caused by the tunnel excavation on surrounding formations.

- The strength of the formations was further degraded due to the impact of the water mainly on the slickensides as well as on the main clay mass (softening).

The creep effect of the clay, which preserves the squeezing - compression on the shell (25th Report of Prof. P. Marinos 1/07/2002). After some balance was temporarily restored in the shell, the continuous deformation (secondary creep) lead to uncontrolled deformations.

"The combination of the aforementioned conditions which exist in Kallidromo tunnel makes this case particularly interesting and unique. Even at the international level there is limited experience in construction and especially in dealing with emergency situations when all the above conditions are present" (Technical Site Report of Dr. Evert Hoek 3/06/2002).

The area was successfully restored with the stiff cross-section S3.A (Fig. 6, 7) which provided for $1 \mathrm{~m}$ full-face boring, $0,6 \mathrm{~m}$ thick steel fibre reinforced shotcrete, spiles $600 \mathrm{Kn} 12 \mathrm{~m}$ long/ $6 \mathrm{~m}$ of tunnel length, fibreglass anchors in the tunnel face, self-drilling anchors $12 \mathrm{~m}(300-600) \mathrm{Kn}, 1$ steel 


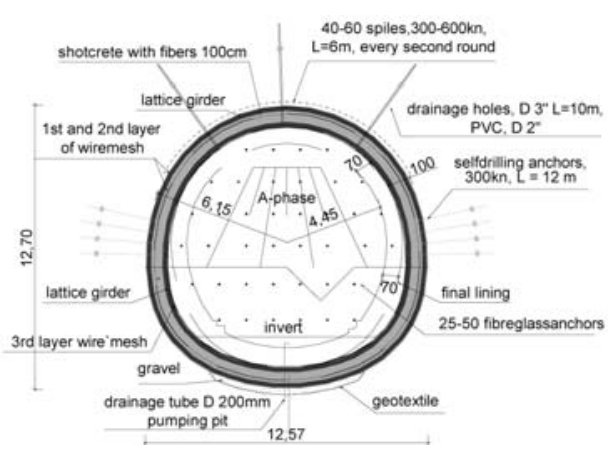

Fig. 10: Yielding - double support cross section.

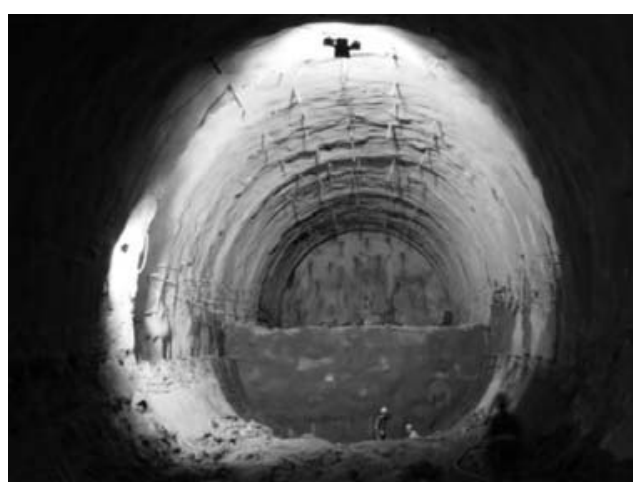

Fig. 11: Yielding - double support.

set HEB 160/m of tunnel length, 4 lattice girders/ $m$ of tunnel length, and two rows of wiremesh.

The retendering of the project provided the opportunity to conduct a wide-range geological - geotechnical plan, and a new final design was performed, which provided that in the "ml" formation the tunnel would be constructed with the yielding support method (Fig. 8, 9). The philosophy of this method is to allow the "soil mass" to converge in a radial direction up to $1 \mathrm{~m}$ by using ten longitudinal gaps in the shotcrete shell (support class Y45g) and special design yielding anchors, before applying a uniform closed ring for the temporary support of the tunnel. This method was applied in two parts of the tunnel, $10 \mathrm{~m}$ long each. The main problems that occurred during construction with the yielding support method are as follows:

- extended face collapses,

- less than anticipated convergence,

- difficulty in placing the yielding anchors,

- fractures in shotcrete segments,

- insecurity of personnel due to unsafe working conditions.

\section{Description of the yielding - double support method}

Based on the experience gained in the previous period, recording and interpreting the behaviour of the "ml" formation and the support class cross-sections, after a series of modifications we have arrived at a new cross-section, combining the principles of the yielding $\&$ the stiff support (double support).The tunnel is excavated in two phases (Fig. 10, 11), the distance between them being over $6,00 \mathrm{~m}$. During the A phase (top heading) the advance step is $(0,70-1,00) \mathrm{m}$, a coating of category $\mathrm{C} 30 / 3735 \mathrm{~cm}$ thick shotcrete is applied, 3 steel lattice girders type Pantex $100 / 20 / \mathrm{m}$ of tunnel length are placed, as well as 2 sets of wiremesh and $8 \mathrm{pc} 12,00 \mathrm{~m}$ long $/ \mathrm{m}$ of tunnel length, self-drilling anchors, with a bearing capacity of $300 \mathrm{Kn}$. The tunnel face is reinforced with fibreglass anchors with a capacity of $200 \mathrm{Kn}$ every $5,00 \mathrm{~m}$ of tunnel length or five days advance, and the roof is secured with spiles $\{6,00 \mathrm{~m}$ long self-drilling anchors with a bearing capacity of (300 or 600)Kn every second round\}. The behaviour of the support is closely monitored with closely-spaced sets of instruments consisting of convergence points every (515)m, anchor load cells, shotcrete load cells every (20-30)m and extensometers every about 100m.

Based on all the information gathered it was decided that the excavation bench would follow the top heading at a distance of about $18 \mathrm{~m}$ or a time-distance of about 5 days, in order to allow for the partial unloading of the soil mass with displacements of up to approximately $15 \mathrm{~cm}$. It is noted that anchors are only placed in the tunnel sides (4 items per tunnel side) in order to minimize convergences and facilitate settlements, since no prevention measure was taken (elephant 


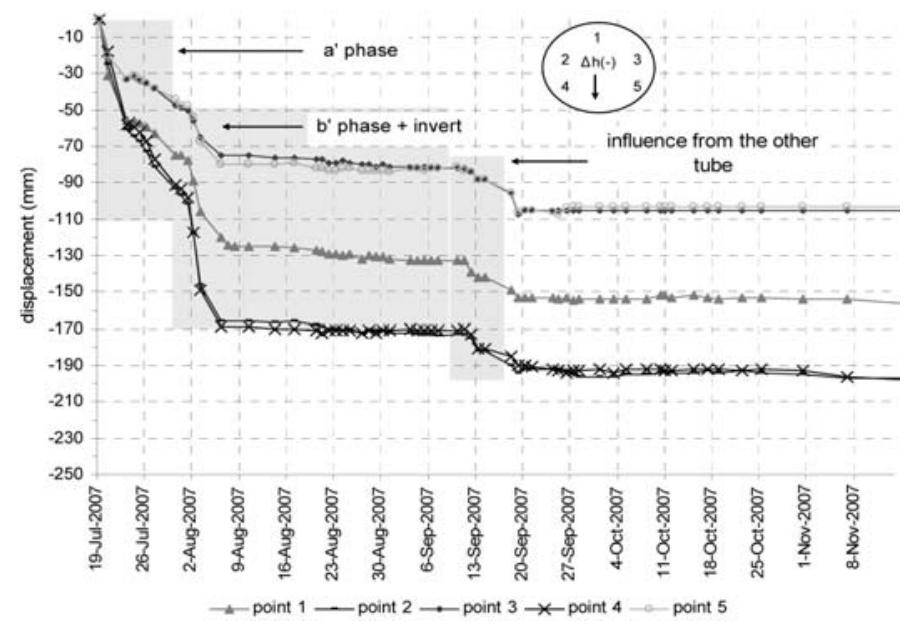

Fig. 12: Vertical Displacements during excavation and primary support.

foot, micropiles, temporary invert etc).

Once the allowable settlements and convergences are completed, we proceed with the excavation of B phase (bench \& invert with an advance step of $3 \mathrm{~m}$ ), during which the same support measures are applied as in the top heading, except for the placement of anchors. Then a second support ring is constructed, made of strong wiremesh, one steel lattice girder type Pantex 100/20 per running meter and $65 \mathrm{~cm}$ thick steel fibre reinforced shotcrete of category C30/37, thus fully completing the temporary support of the tunnel.

Moreover, after the completion of the internal ring, an allowance of $0,2 \mathrm{~m}$ is taken into account, in case additional support measures need to be applied. However, such measures have not been necessary.

With this method the progress rate achieved is $(30-35) \mathrm{m}$ of excavation and temporary support per tunnel tube per month, working 24 hours a day 7 days a week.

\section{Instrumentation monitoring}

Instrumentation monitoring both during construction and after completion of the temporary support has revealed interesting information about clay behaviour.

First of all, during top heading construction the rate of lateral displacements (convergences) was relatively low, namely $1 \mathrm{~cm}$ per day, as opposed to vertical displacements, which reached up to $3 \mathrm{~cm}$ per day. When the temporary support was completed displacements practically disappeared, as shown in the displacement diagram (Fig. 12). It is also worth noting in the diagram the impact on the cross-section caused by the excavation bench and the invert, as well as by the adjacent tube. Extensometers indicated a loosening zone extending over 15,0m, which loosened within 3-4 days from the excavation of the face. Anchor load cell measurements have shown that initially the load of anchors placed at the vertical benches exceeded their strength (over $300 \mathrm{Kn}$ ), where as anchors placed higher were barely or not loaded. For this reason it was decided not to install anchors higher than $3 \mathrm{~m}$ of the A phase working level. Instead the cross-section was reinforced at the vertical benches by installing four anchors per running meter in each side, placed in triangular grid configuration. As a result, anchors were evenly loaded and the load did not exceed anchor limits. Following the completion of the internal support ring, anchors were quickly unloaded until the load almost reached zero. This behaviour is compatible with the indications taken from the extensometers. 


\section{Problems in the application of the method}

During the application of the support method described above, the following problems have occurred:

Problems caused by "ml" behaviour uncertainty both during excavation and after the completion of the support. Before the sequence of works could be stabilized, the excavation procedure was modified both in terms of timing and with respect to the type of support used, and as a result progress rate was very low. Moreover, it was deemed necessary to open an additional crosscut and install the final lining, in order to secure the first $270 \mathrm{~m}$ of the $645 \mathrm{~m}$ that were driven in total in each tube inside the clay-marl formation.

Problems caused by the instability of the excavation faces. Frequent collapses of the excavation faces due to circular or plane slips that caused overexcavations and delays in the progress of works. This problem was adequately addressed through partial excavation, face buttress, and installation of spiles and fibreglass face anchors.

Another major challenge was the presence of large quantities of water $\left(70 \mathrm{~m}^{3} /\right.$ hour $)$ in the sand layers that were inside the "ml" mass, resulting in the creation of instable conditions in the excavation face, combined with the presence of abundant mud on the work floor, which made construction works difficult.

The difficulty of placing large quantities of very thick shotcrete (in the order of $65 \mathrm{~cm}$ ) was overcome through the use of appropriate concrete compositions.

Finally, construction costs were rather high due to the large quantities of shotcrete; however, it is noted that this cost is lower than the cost of the tunnel sections that needed to be repaired or reconstructed.

\section{Conclusions}

It can be concluded that the yielding support - double ring method has been proven successful. During the tunnel excavation and support, as well as after the completion of the primary lining, the ring behaviour was predictable and showed minimum deviations, mainly at the excavation face.

With this method approximately $1100 \mathrm{~m}$ of the tunnel have been completed, admittedly under very difficult geological conditions, and the project's technical staff is optimistic regarding the completion of the biggest tunnel in Greece.

\section{References}

Office Malios S.A.. Final design study of the Kallidromo tunnel for the constructive joint venture, 1998.

E. Hoek, unpublished site report, 3/6/2002.

P. Marinos, Professor of National Technical University of Athens, unpublished site report, 1/7/2002.

M. H. Aleksiadou, Geological design study of the Kallidromo tunnel for Ergose Company, 2003.

W. Wittke Professor Dr. Engineer, NAMA S.A, Final design study of the Kallidromo tunnel for Ergose Company, 2003.

K. Mitsugi, Y. Kajiwara, Construction of the 3rd longest mountain tunnel in the world - Excavation of swollen and soft mudstone layers, AITES - ITA 2001 World Tunnel Congress, Volume III. 